\title{
Cost Analysis of Diffusion Tensor Imaging and MR Tractography of the Brain
}

\author{
Christopher Hancock, Byron Bernal, Camila Medina, Santiago Medina \\ Miami Children's Hospital, Miami, USA \\ Email: chancockmd@gmail.com
}

Received 18 June 2014; revised 15 July 2014; accepted 30 July 2014

Copyright $@ 2014$ by authors and Scientific Research Publishing Inc.

This work is licensed under the Creative Commons Attribution International License (CC BY). http://creativecommons.org/licenses/by/4.0/

(c) (7) Open Access

\begin{abstract}
Purpose: To determine the total direct costs (fixed and variable costs) of diffusion tensor imaging (DTI) and MR tractography reconstruction of the brain. Materials and Methods: The direct fixed and variable costs of DTI with MR tractography were determined prospectively with time and motion analysis in a 1.5-Tesla MR scanner using 15 encoding directions. Seventeen patients with seizure disorders, 9 males \& 8 females, with mean age of 13 years (age range 2 - 33 years) were studied. Total direct costs were calculated from all direct fixed and variable costs. Sensitivity analyses between 1.5 versus a 3-Tesla MR system, and 15 versus 32 encoding directions were done. Results: The total direct costs of DTI and MR tractography for a 1.5-T system with 15 encoding directions were US $\$ 97$. Variable cost was $\$ 76.80$ and fixed cost was $\$ 20.20$. Total direct costs for a 3-T system with 15 directions decreased to US $\$ 94.5$ because of the shorter scan time despite the higher cost of the 3-T system. The most costly component of the direct cost was post-processing analysis at US \$46.00. Conclusion: DTI with MR tractography has important total direct costs with variable costs higher than the fixed costs. The post processing variable cost is the most expensive component. Developing more accurate automated post-processing software for DTI and MR tractography is important to decrease this variable labor cost. Given the added value of DTI-MR tractography and the costs involved reimbursement codes should be considered.
\end{abstract}

\section{Keywords}

Tractography, Diffusion Tensor Imaging, MRI, Pediatrics, Brain, Cost Analysis, Functional

\section{Introduction}

Diffusion Tensor Imaging (DTI) is currently the most sensitive MR-technique utilized to assess white matter integrity [1]. DTI is based on a mathematical description (the tensor) of the 3D shape of the water diffusion occur- 
ring in a fibrillary organized tissue (e.g. the brain) [2]. Fractional anisotropy (FA) and mean diffusivity are scalars that describe the asymmetry of such diffusion; the asymmetry is due to the barriers of the myelin sheet of the axons and cell membranes [3]. DTI images are coded with respect to the FA, the diffusivity (ADC), or the predominant direction of the tensor [4]. From these maps, it is possible to perform 3D-reconstructions of brain white matter using MR tractography (MRT) [5] [6]. The localization of white matter tracts in the brain has been demonstrated as an important factor affecting pre-surgical planning, counseling, and outcome [7]-[10]. In addition DTI is important in traumatic brain injury as an outcome surrogate [11] [12]. Therefore, there is mounting evidence of the added clinical value of diffusion tensor imaging and MR tractography in these patient populations [13]. However, this study requires additional sequences and rigorous imaging post processing hence, incurring additional scanning time and use of personnel resources. However, to our knowledge, no rigorous cost analysis of DTI and MR tractography has been done to determine the exact resources used and its exact cost, though some attempts have been made to characterize value [13]-[15]. The purpose of our study, therefore, was to determine the total direct costs (fixed and variable costs) of DTI and MR tractography [16].

\section{Materials and Methods}

The inclusion of patients in this prospective study was based on the following criteria: history of seizures, consideration for surgical treatment, and resultant need for evaluation of potentially involved eloquent white matter tracts. Institutional review board approval was obtained. Informed consent was obtained for all patients studied [17]. Between February 2006 and July 2010, 17 patients (9 males and 8 females) between 2 - 33 years of age with a mean age and standard deviation of 13 years \pm 4 years were recruited and evaluated by DTI and MR tractography at Miami Children's Hospital. Demographic and clinical data for the patients evaluated are shown in Table 1.

A flowchart of the procedure used for DTI and MRI is shown in Figure 1.

After the procedure was explained to the patient and guardian, the patient was positioned in a 1.5-T MR imager (Philips Intera, Philip Medical Systems software release V. 11) utilizing a SENSE head coil. All subjects had a 15-gradient direction scan DTI sequence, performed with a single-shot, spin-echo-planar imaging sequence with diffusion weighting. A single reference volume with no diffusion weighting was obtained; diffusion weighting (b) of $800 \mathrm{~s} / \mathrm{mm}^{2}$; repetition time of $8326 \mathrm{~ms}$; echo time of $94 \mathrm{~ms}$; number of excitations 3; FOV of $240 \times 240 \mathrm{~mm}^{2}$; scan matrix of $112 \times 112$; reconstruction matrix $256 \times 256$; 502 -mm axial slices and no slice gap. Images were transferred to the post-processing work station where FA, mean diffusivity, and color anisotropy maps were generated in the axial, sagittal and coronal planes utilizing Volume-One

(http://www.volume-one.org). Eddy current artifacts were minimized by the intra-sequence registration tool utilized in the post-processing analysis [18] [19]. Subsequently a neurologist and/or a computer scientist selected

\begin{tabular}{cc}
\hline Table 1. Study population demographics. & \\
\hline Parameter & DTI and MR tractography \\
\hline No. of patients & 17 \\
Male & 9 \\
Female & 8 \\
Age range & $2-33$ \\
Age (y) $^{\dagger}$ & $13 \pm 8$ \\
Tumor & 9 \\
Vascular malformations & 3 \\
Not biopsied & 3 \\
Cortical dysplasia & 1 \\
Abscess & 1 \\
\hline
\end{tabular}

Note: Data are numbers of patients unless otherwise indicated. * Years;

${ }^{\dagger}$ Mean \pm standard deviation in years. 


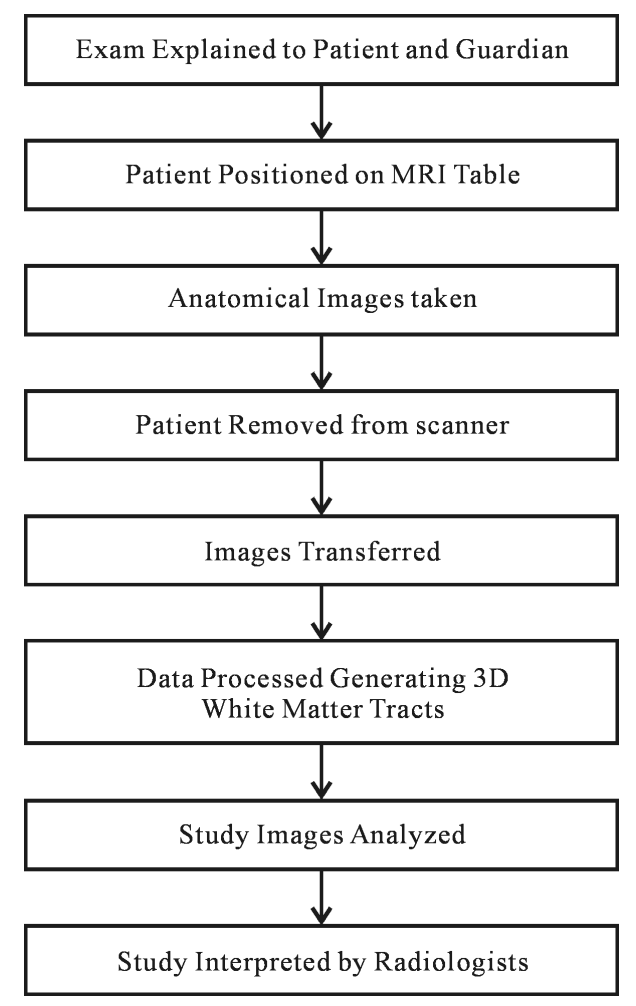

Figure 1. Flowchart of diffusion tensor MR imaging.

the regions of interest (ROI) to generate the three dimensional white matter tracts and calculate the ROI-based FA and diffusivity values. Tractography was performed using a region-growing algorithm that merges voxels having similar tensor direction in neighboring voxels of the seeding ROI [20]. Thresholds for the tracking algorithm were set at 0.15 for $\mathrm{FA}$, and $45^{\circ}$ for maximum voxel-to-voxel fiber bending, as has been interrogated previously [21]. White matter tracts generated included corpus callosum, corticospinal tracts in the internal capsules, superior longitudinal and arcuate fasciculi, plus the inferior fronto-occipital fasciculi [22] [23]. Subsequently, the images were interpreted by a radiologist and a report was generated. The radiologist's interpretation time was recorded. Time needed for notification or discussion with the referring physician, was not included in the analysis. Teaching time was not included either in the analysis. From entries in the departmental logbook, the mean daily use of the MR scanner was determined to be 14 hours.

\subsection{Definition of Costs}

Costs were categorized as direct or indirect [24]-[27]. Direct costs were those directly associated with the performance of the examination and included fixed and variable costs, according to the system of classification used by the US Panel on Cost Effectiveness in Health and Medicine and by our medical center's cost accounting departments [28]. Fixed costs were those that did not change with the procedure, such as costs of equipment purchase, maintenance service contract, physical housing such as shielding, and depreciation [29]. Variable costs were those that depended on the procedure, such as costs of labor (MR technologist, post processing personnel and radiologist) and supplies (e.g., hardware and software for image creation and storage) [30]. Indirect costs are those incurred independently of the procedure, including expenses for grounds (e.g., walkways, parking areas, and landscaping) and general administration, human resources, utilities, housekeeping and general maintenance [31]. Because indirect costs are incurred regardless of the procedure performed, they were excluded from the statistical analysis.

In this study, fixed direct costs included the costs of equipment purchase, depreciation, maintenance, and service [32]. Variable direct costs included the costs of labor and materials directly attributable to the performance 
of the procedures [27]. Cost analysis was performed from a medical center perspective [33] [34]. All costs were adjusted to year 2010 US dollars.

\subsection{Measurement of Costs}

The direct fixed and variable costs of DTI with MR tractography were determined prospectively with time and motion analysis methodology [24].

\subsubsection{Fixed Direct Costs}

All fixed direct costs were determined from accounting records of the medical centers. The fixed direct costs of each patient examination were based on utilization calculations and on total costs incurred during the measurement period, as reported in the management departmental logbooks [27] [28] [30]. Fixed costs of equipment were calculated on the basis of assumed 5-year linear depreciation, in accordance with guidelines of the American Hospital Association Health Data and Coding Standards Group [27] [28] [30].

\subsubsection{Variable Direct Costs}

Variable direct costs were tracked using a standardized form for all patients studied [24]. All materials used during the procedures were recorded, and their costs were assigned on the basis of the actual prices paid by the medical center's purchasing department.

Labor costs were measured with time and motion analysis. The amount of time spent by personnel involved in patient examinations and post procedural care was recorded to the nearest minute and entered into the time and motion analysis model. Laborers included physicians, technologists and post processing personnel. For salaried workers, labor cost calculations were based on total annual compensation, including benefits and salary, divided by the estimated number of billable labor hours per year [35]. The time spent by radiologists in image interpretation was also measured. All images were interpreted and reported by the attending radiologist. Teaching time was not included as part of the analysis.

\subsection{Statistical Analysis}

Total direct costs were tabulated for each examination and classified as either fixed or variable costs [36]. Variable direct costs were further subdivided into variable costs of computer scientist and neurologist postprocessing, radiologist, MR technologist and storage cost. Table 2 shows the unit cost estimates used in the analysis.

\begin{tabular}{|c|c|}
\hline Resource & \\
\hline Purchase of 1.5-T MR imager with shielding costs & $2,000,000$ \\
\hline Purchase of 3.0-T MR Imager with shielding costs & $3,000,000$ \\
\hline Yearly service and maintenance contract for 1.5-T MR imager & 120,000 \\
\hline Purchase and yearly service DTI and MR tractography & 6000 \\
\hline Yearly service DTI MR imaging post processing software \& workstation & 5500 \\
\hline Weekly use of 1.5-T MR imager (h) & 70 \\
\hline Cost of images storage & $3-7$ \\
\hline Hourly salary per radiologist & 150 \\
\hline Hourly salary per MR technologist & 30 \\
\hline Hourly salary per DTI computer scientist & 41 \\
\hline Hourly salary per neurologist & 67 \\
\hline
\end{tabular}

Cost in 2010 US dollars unless otherwise specified. 
Means ( \pm SDs) for each cost category were calculated [37]-[39]. Sensitivity analyses were performed for important cost variables including a 3-Tesla MR scanner and using the longer 32 direction DTI sequence. Spreadsheet software (Excel; Microsoft, Redmond, Washington) was used in the statistical analysis.

\section{Results}

The direct fixed and variable costs of examination with DTI and MR tractography are shown in Table 3, and relative correlations are expected among various vendors given the disparate costs of acquisition and purchasing of 1.5-T vs. 3-T systems.

The mean total direct cost was $\$ 97$ with a range of $\$ 73.22$ to $\$ 115.65$. The mean direct fixed cost was $\$ 20.20$ representing $20.8 \%$ of the total direct costs. The mean direct variable cost was almost four times higher than the fixed cost at $\$ 76.80$ representing $78.2 \%$ of the total direct costs. The largest components of the variable costs were the post-processing costs by the computer scientist and neurologist at $\$ 31.43$ and $\$ 13.95$, respectively for a total of $\$ 45.38$. This represents $59.1 \%$ of the total variable costs and $46.4 \%$ of the total direct costs. This is the largest cost component since post-processing and generation of the 3-D tractography images is labor intensive requiring in average 46 minutes for the computer scientist and 12.5 minutes for the neurologist. Radiologist interpretation of the study was less labor intensive with a mean of 10 minutes at an average variable cost of $\$ 25.00$.

\section{Sensitivity Analyses}

Sensitivity analyses for 1.5 versus 3-Tesla MR system and 15 versus 32 directions were done. Results are shown in Table 4 and Figure 2.

Scanning time increased when DTI was done with 32 directions in the 1.5-Tesla MR system, hence, increasing the mean total direct cost to $\$ 113.70$.

Overall total direct costs between the 1.5 and the 3-Tesla systems were similar at comparable number of directions with differences under three dollars (Table 4). However, there was an increase of greater than ten percent in total direct costs for both Tesla systems when the directions were increased from 15 to 32 because of

Table 3. Direct fixed and variable costs for DTI and MR tractography at 1.5-Tesla with 15 directions.

\begin{tabular}{ccc}
\hline Cost category & Test mean (\%) & Range \\
\hline Fixed cost (\$) & $20.2(20.8)$ & $19.25-21$ \\
Variable costs (\$) & $76(78.2)$ & $53.97-94.85$ \\
Computer scientist post-processing & 31.43 & $23.9-34$ \\
Neurologist post-processing & 13.95 & $11.17-16.75$ \\
Radiologist interpretation & 25 & $12.50-37.50$ \\
MR technologist & 4.50 & $3.95-4.95$ \\
Transcription and voice recognition & 1.9 & $74.14-114.82$ \\
Storage cost & 2.55 & 97 \\
\hline
\end{tabular}

\begin{tabular}{|c|c|c|c|c|c|c|}
\hline & Average minutes & Total cost & Fixed cost & FC (\%) & Variable cost ${ }^{*}$ & VC (\%) \\
\hline 1.5-T@15 directions & 9 & $\$ 97.0$ & $\$ 20.2$ & (20.8) & $\$ 76.8$ & $(79.2)$ \\
\hline 1.5-T@ 32 directions & 16 & $\$ 113.7$ & $\$ 33.4$ & (29.4) & $\$ 80.3$ & (70.6) \\
\hline 3-T @15 directions & 6.1 & $\$ 94.5$ & $\$ 19.1$ & $(20.2)$ & $\$ 75.3$ & (79.8) \\
\hline 3-T @32 directions & 11.7 & $\$ 111.9$ & $\$ 33.8$ & $(30.2)$ & $\$ 78.1$ & (69.8) \\
\hline
\end{tabular}

${ }^{*}$ Mean-post processing cost $\$ 45.38$. 


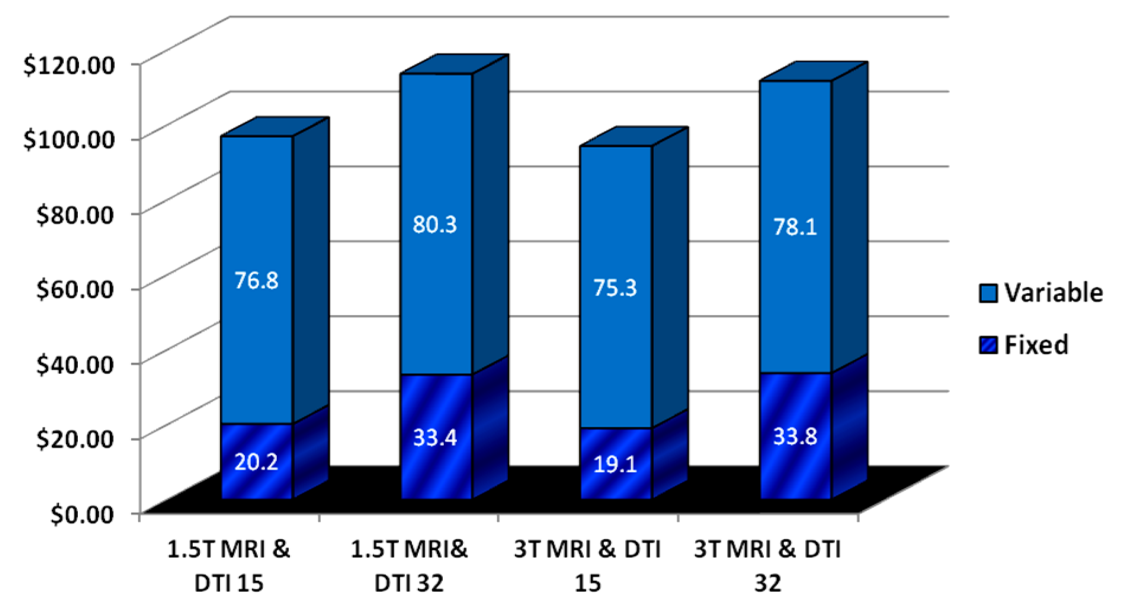

Figure 2. Fixed, variable, \& total costs for DTI 1.5 MRI vs. DTI 3.0 MRI.

significant increase in scanning time (Table 4).

Scanning times were less on the 3-Tesla MR system for both the 15 and 32 directions given the higher signal to noise ratio and hence shorter scan time (Table 4). Although the 3-Tesla MR system is overall more expensive than the 1.5-Tesla MR system, the time scanning reduction produced overall a small decrease in the 3-Tesla total direct cost being $\$ 94.5$ for 15 directions and $\$ 111.9$ for 32 directions. This mild decrease in cost is primarily due to the mild decrease in MR technologist variable cost given the shorter scanning times.

\section{Discussion}

The results of this study indicate that performing DTI and MR tractography uses significant resources which incur on fixed and variable cost with total direct cost in the range of $\$ 94.5$ and $\$ 113.70$. There is no significant difference in the total direct cost between 1.5- and 3-Tesla MR systems at comparable number of directions. However, for both systems there is a just over ten percent increase in cost by increasing the total directions from 15 to 32. There is mounting clinical research data showing the added value of DTI and MR tractography in seizure and brain neoplasm neurosurgical planning plus traumatic brain injury, therefore separate test generation and reporting with an appropriate reimbursement or CPT code should be considered.

The most expensive cost component of DTI and MR tractography is the post processing costs accounting for a mean variable cost of $\$ 45.38$ (46.4\% of the total direct costs). Further development of more robust automated MR tractography software incorporating artificial intelligence should be done to decrease this time consuming process and hence, decrease variable costs.

Cost analysis of other advanced brain MR imaging has been done using similar methodology. The mean total direct cost of functional MR imaging is \$301.82 [24]. Therefore, the mean total direct cost of DTI and MR tractography is about a third of functional MR imaging. Functional MR imaging has added value by providing information about eloquent brain areas in seizure and brain neoplasm patients being consider for surgical intervention [40]-[43]. DTI and MR tractography also provides added value in this population by depicting the tracts which connect these eloquent brain areas [1] [44]-[48]. Given functional MR imaging added value and costs approved CPT codes are currently available for reimbursement purposes [49]. Although DTI and MR tractography have added diagnostic value no CPT codes are currently available to pay for their significant total direct costs [50]-[52]. Therefore consideration into developing specific reimbursement or CPT codes for DTI and MR tractography should be consider given its added value and additional total direct cost not covered by conventional brain MRI.

We chose to define costs from the perspective of the medical center because managed health care and discounted fee for service have become the predominant models of health care expense reimbursement in the United States [53]-[57]. With capitation, health care providers bear the burden of actual costs and have no possibility of reimbursement for expenses that exceed prepaid premiums [58]. To maintain appropriate net revenue, health care providers must know the costs of each procedure. Our time and motion analyses of direct fixed variable costs enabled rigorous quantification and eliminated the assumptions inherent in estimated cost measure- 
ment [55] [59]-[63], charge-based analyses [64]-[67], analyses based on ratio of costs to charges [68]-[74], and relative value unit-based analyses [75] [76]. Our results, however, may not be generalizable to all medical institutions and centers. First, the data used in this study was collected from one institution rather than from multiple medical centers with different physician and patient constituencies. Furthermore, because all costs, particularly those of labor, are based on regional standards, the absolute costs reported in this study may diverge from absolute costs incurred in other regions. The relative costs, however, should be generalizable to most institutions in the United States [77].

\section{Conclusion}

In conclusion, DTI and MR tractography have significant total direct costs and resource utilization. No significant cost difference is seen between 1.5- and 3-Tesla MR systems for comparable number of directions used. However, the increase in directions from 15 to 32 increases the total direct cost just over $10 \%$ for both Tesla systems. Post processing is the most expensive component of this test. Therefore, further development of faster and robust post-processing software is a priority to decrease overall total direct costs. Given the increasing research data showing the added value of DTI-MR tractography, dedicated reimbursement CPT codes must be developed so appropriate cost compensation is ensued given the additional resources utilized for this useful test.

\section{References}

[1] Assaf, Y. and Pasternak, O. (2008) Diffusion Tensor Imaging (DTI)-Based White Matter Mapping in Brain Research: A Review. Journal of Molecular Neuroscience, 34, 51-61. http://dx.doi.org/10.1007/s12031-007-0029-0

[2] Hagmann, P., et al. (2003) DTI Mapping of Human Brain Connectivity: Statistical Fibre Tracking and Virtual Dissection. Neuroimage, 19, 545-554. http://dx.doi.org/10.1016/S1053-8119(03)00142-3

[3] Mukherjee, P., et al. (2008) Diffusion Tensor MR Imaging and Fiber Tractography: Theoretic Underpinnings. American Journal of Neuroradiology, 29, 632-641. http://dx.doi.org/10.3174/ajnr.A1051

[4] Klose, U., et al. (2005) Segmentation of the White Matter in the Brain Based on MR-DTI Fiber Directions. Zeitschrift für Medizinische Physik, 15, 247-255.

[5] Sanchez, D., et al. (2006) 3-D Brain Segmentation towards the Integration of DTI and MRI Modalities. Biomedical Sciences Instrumentation, 42, 326-331.

[6] Holdsworth, S.J., et al. (2012) Diffusion Tensor Imaging (DTI) with Retrospective Motion Correction for Large-Scale Pediatric Imaging. Journal of Magnetic Resonance Imaging, 36, 961-971. http://dx.doi.org/10.1002/jmri.23710

[7] Qiu, T.M., et al. (2010) Virtual Reality Presurgical Planning for Cerebral Gliomas Adjacent to Motor Pathways in an Integrated 3-D Stereoscopic Visualization of Structural MRI and DTI Tractography. Acta Neurochirurgica (Wien), 152, 1847-1857. http://dx.doi.org/10.1007/s00701-010-0739-x

[8] Radhakrishnan, A., et al. (2011) Utility of Diffusion Tensor Imaging Tractography in Decision Making for Extratemporal Resective Epilepsy Surgery. Epilepsy Research, 97, 52-63. http://dx.doi.org/10.1016/j.eplepsyres.2011.07.003

[9] van der Aa, N.E., et al. (2011) Does Diffusion Tensor Imaging-Based Tractography at 3 Months of Age Contribute to the Prediction of Motor Outcome after Perinatal Arterial Ischemic Stroke? Stroke, 42, 3410-3414. http://dx.doi.org/10.1161/STROKEAHA.111.624858

[10] Jang, S.H., et al. (2008) Motor Outcome Prediction Using Diffusion Tensor Tractography in Pontine Infarct. Annals of Neurology, 64, 460-465. http://dx.doi.org/10.1002/ana.21444

[11] Newcombe, V., Chatfield, D., Outtrim, J., Manktelow, A., Coles, J., Menon, D., et al. (2011) Mapping Traumatic Axonal Injury Using Diffusion Tensor Imaging: Correlations with Functional Outcome. PLoS ONE, 6, e19214. http://dx.doi.org/10.1371/journal.pone.0019214

[12] Levin, H.S., Wilde, E.A., Chu, Z.L., Yallampalli, R., Hanten, G.R., Li, X.Q., Chia, J., Vasquez, A.C. and Hunter, J.V. (2008) Diffusion Tensor Imaging in Relation to Cognitive and Functional Outcome of Traumatic Brain Injury in Children. Journal of Head Trauma Rehabilitation, 23, 197-208. http://dx.doi.org/10.1097/01.HTR.0000327252.54128.7c

[13] Karmonik, C., Dulay, M., Verma, A. and Grossman, R.G. (2010) Cost Function Evaluation for the Registration of Clinical DTI Images onto the ICBM DTI81 White Matter Atlas. Technology and Health Care, 18, 145-156.

[14] Bertani, G., Carrabba, G., Raneri, F., Fava, E., Castellano, A., Falini, A., Casarotti, A., Gaini, S.M. and Bello, L. (2012) Predictive Value of Inferior Fronto-Occipital Fasciculus (IFO) DTI-Fiber Tracking for Determining the Extent of Resection for Surgery of Frontal and Temporal Gliomas Preoperatively. Journal of Neurosurgical Sciences, 56, 137-143.

[15] Lascola, C.D. (2005) Diffusion Tensor Tractography: Exploring the Cost-Benefit Ratio of Incorporating CSF Suppres- 
sion into Fiber Tracing Algorithms. AJNR American Journal of Neuroradiology, 26, 693-694.

[16] Siegel, J.E., Weinstein, M.C., Russell, L.B. and Gold, M.R. (1996) Recommendations for Reporting Cost-Effectiveness Analyses. Panel on Cost-Effectiveness in Health and Medicine. JAMA, 276, 1339-1341. http://dx.doi.org/10.1001/jama.1996.03540160061034

[17] Kiguba, R., Kutyabami, P., Kiwuwa, S., Katabira, E. and Sewankambo, N.K. (2012) Assessing the Quality of Informed Consent in a Resource-Limited Setting: A Cross-Sectional Study. BMC Medical Ethics, 13, 21. http://dx.doi.org/10.1186/1472-6939-13-21

[18] Tsao, J., Kozerke, S., Boesiger, P. and Pruessmann, K.P. (2005) Optimizing Spatiotemporal Sampling for k-t BLAST and k-t SENSE: Application to High-Resolution Real-Time Cardiac Steady-State Free Precession. Magnetic Resonance in Medicine, 53, 1372-1382. http://dx.doi.org/10.1002/mrm.20483

[19] Finsterbusch, J. (2009) Eddy-Current Compensated Diffusion Weighting with a Single Refocusing RF Pulse. Magnetic Resonance in Medicine, 61, 748-754. http://dx.doi.org/10.1002/mrm.21899

[20] Klose, U., Mader, I., Unrath, A., Erb, M. and Grodd, W. (2004) Directional Correlation in White Matter Tracks of the Human Brain. Journal of Magnetic Resonance Imaging, 20, 25-30. http://dx.doi.org/10.1002/jmri.20086

[21] Wang, K., Zhu, S., Mueller, B.A., Lim, K.O., Liu, Z.M. and He, B. (2008) A New Method to Derive White Matter Conductivity from Diffusion Tensor MRI. IEEE Transactions on Biomedical Engineering, 55, 2481-2486. http://dx.doi.org/10.1109/TBME.2008.923159

[22] Wassermann, D., Bloy, L., Kanterakis, E., Verma, R. and Deriche, R. (2010) Unsupervised White Matter Fiber Clustering and Tract Probability Map Generation: Applications of a Gaussian Process Framework for White Matter Fibers. NeuroImage, 51, 228-241. http://dx.doi.org/10.1016/j.neuroimage.2010.01.004

[23] Wassermann, D., Rathi, Y., Bouix, S., Kubicki, M., Kikinis, R., Shenton, M. and Westin, C.F. (2011) White Matter Bundle Registration and Population Analysis Based on Gaussian Processes. Information Processing in Medical Imaging, 22, 320-332.

[24] Medina, L.S., Aguirre, E., Bernal, B. and Altman, N.R. (2004) Functional MR Imaging versus Wada Test for Evaluation of Language Lateralization: Cost Analysis. Radiology, 230, 49-54. http://dx.doi.org/10.1148/radiol.2301021122

[25] James, P., Bebee, P., Beekman, L., Browning, D., Innes, M., Kain, J., Royce-Westcott, T. and Waldinger, M. (2011) Effort Tracking Metrics Provide Data for Optimal Budgeting and Workload Management in Therapeutic Cancer Clinical Trials. Journal of the National Comprehensive Cancer Network, 9, 1343-1352.

[26] Baltussen, R., Acharya, A., Antioch, K., Chisholm, D., Grieve, R., Kirigia, J., Torres-Edejer, T.T., Walker, D.G. and Evans, D. (2009) Cost-Effectiveness and Resource Allocation (CERA)-Directions for the Future. Cost Effectiveness and Resource Allocation, 7, 14. http://dx.doi.org/10.1186/1478-7547-7-14

[27] Ziran, B.H., Barrette-Grischow, M.K. and Marucci, K. (2008) Economic Value of Orthopaedic Trauma: The (Second to) Bottom Line. Journal of Orthopaedic Trauma, 22, 227-233. http://dx.doi.org/10.1097/BOT.0b013e31816bae67

[28] Brauer, C.A., Rosen, A.B., Greenberg, D. and Neumann, P.J. (2006) Trends in the Measurement of Health Utilities in Published Cost-Utility Analyses. Value in Health, 9, 213-218. http://dx.doi.org/10.1111/j.1524-4733.2006.00116.x

[29] Mitsutake, N., Oku, S., Fujii, R., Furui, Y. and Yasunaga, H. (2008) Business Administration of PET Facilities: A Cost Analysis of Three Facilities Utilizing Delivery FDG. Kaku Igaku, 45, 119-123.

[30] Sistrom, C.L. and McKay, N.L. (2005) Costs, Charges, and Revenues for Hospital Diagnostic Imaging Procedures: Differences by Modality and Hospital Characteristics. Journal of the American College of Radiology, 2, 511-519. http://dx.doi.org/10.1016/j.jacr.2004.09.013

[31] Glaser, J. and Sett, A. (2012) Using Technology to Reveal True Costs. Healthcare Financial Management, 66, 44-49.

[32] Sharara, N., Adam, V., Crott, R. and Barkun, A.N. (2008) The Costs of Colonoscopy in a Canadian Hospital Using a Microcosting Approach. Canadian Journal of Gastroenterology, 22, 565-570.

[33] Rego, G., Nunes, R. and Costa, J. (2010) The Challenge of Corporatisation: The Experience of Portuguese Public Hospitals. European Journal of Health Economics, 11, 367-381. http://dx.doi.org/10.1007/s10198-009-0198-6

[34] Rinker, G. (1995) Cost Accounting Applied to the Clinical Laboratory. Clinical Laboratory Science, 8, 339-342.

[35] Weiss, M., Martin, J., Feser, U., Schafmayer, C. and Bauer, M. (2005) Necessity and Problems with Case-Related Costing for Intensive Care Patients. Der Anaesthesist, 54, 254-262. http://dx.doi.org/10.1007/s00101-005-0805-6

[36] Bell, R.A. (1996) Economics of MRI Technology. Journal of Magnetic Resonance Imaging, 6, 10-25. http://dx.doi.org/10.1002/jmri.1880060105

[37] Hennekens, C.B. and Buring, J.E. (1987) Epidemiology in Medicine. Little, Brown, Boston, 252-258.

[38] Rosner, B. (1995) Fundamentals of Biostatistics. 4th Edition, Duxbury, Belmont, 141-190.

[39] Glantz, S. (1987) Primer of Biostatistics. 2nd Edition, McGraw-Hill, New York. 
[40] Rasmussen Jr., I.A., Lindseth, F., Rygh, O.M., Berntsen, E.M., Selbekk, T., Xu, J., et al. (2007) Functional Neuronavigation Combined with Intra-Operative 3D Ultrasound: Initial Experiences during Surgical Resections Close to Eloquent Brain Areas and Future Directions in Automatic Brain Shift Compensation of Preoperative Data. Acta Neurochirurgica, 149, 365-378. http://dx.doi.org/10.1007/s00701-006-1110-0

[41] Sherman, J.H., Hoes, K., Marcus, J., Komotar, R.J., Brennan, C.W. and Gutin, P.H. (2011) Neurosurgery for Brain Tumors: Update on Recent Technical Advances. Current Neurology and Neuroscience Reports, 11, 313-319. http://dx.doi.org/10.1007/s11910-011-0188-9

[42] Gonzalez-Darder, J.M., González-López, P., Talamantes-Escribá, F., García-March, G., Roldán-Badía, P., Quilis-Quesada, V., et al. (2011) Treatment of Intrinsic Brain Tumors Located in Motor Eloquent Areas. Results of a Protocol Based in Navigation, Tractography and Neurophysiological Monitoring of Cortical and Subcortical Structures. Neurocirugía, 22, 23-35. http://dx.doi.org/10.4321/S1130-14732011000100002

[43] Li, Z.X., Dai, J.P., Jiang, T., Li, S.W., Sun, Y.L., Liang, X.L. and Gao, P.Y. (2006) Function Magnetic Resonance Imaging and Diffusion Tensor Tractography in Patients with Brain Gliomas Involving Motor Areas: Clinical Application and Outcome. Chinese Journal of Surgery, 44, 1275-1279.

[44] Caeyenberghs, K., Leemans, A., Geurts, M., Taymans, T., Linden, C.V., Smits-Engelsman, B.C.M., Sunaert, S. and Swinnen, S.P. (2010) Brain-Behavior Relationships in Young Traumatic Brain Injury Patients: DTI Metrics Are Highly Correlated with Postural Control. Human Brain Mapping, 31, 992-1002. http://dx.doi.org/10.1002/hbm.20911

[45] Braus, D.F., Tost, H., Hirsch, J.G. and Gass, A. (2001) Diffusion Tensor Imaging (DTI) and Functional Magnetic Resonance Tomography (fMRI) Expand Methodological Spectrum in Psychiatric Research. Der Nervenarzt, 72, 384-390. http://dx.doi.org/10.1007/s001150050769

[46] Chahboune, H., Ment, L.R., Stewart, W.B., Rothman, D.L., Vaccarino, F.M., Hyder, F. and Schwartz, M.L. (2009) Hypoxic Injury during Neonatal Development in Murine Brain: Correlation between in Vivo DTI Findings and Behavioral Assessment. Cerebral Cortex, 19, 2891-2901. http://dx.doi.org/10.1093/cercor/bhp068

[47] Cirillo, M., Esposito, F., Tedeschi, G., Caiazzo, G., Sagnelli, A., Piccirillo, G., Conforti, R., et al. (2012) Widespread Microstructural White Matter Involvement in Amyotrophic Lateral Sclerosis: A Whole-Brain DTI Study. AJNR American Journal of Neuroradiology, 33, 1102-1108. http://dx.doi.org/10.3174/ajnr.A2918

[48] Ding, A.Y., Chan, K.C. and Wu, E.X. (2012) Effect of Cerebrovascular Changes on Brain DTI Quantitation: A Hypercapnia Study. Magnetic Resonance Imaging, 30, 993-1001. http://dx.doi.org/10.1016/j.mri.2012.02.012

[49] Bobholz, J.A., Rao, S.M., Saykin, A.J. and Pliskin, N. (2007) Clinical Use of Functional Magnetic Resonance Imaging: Reflections on the New CPT Codes. Neuropsychology Review, 17, 189-191. http://dx.doi.org/10.1007/s11065-007-9022-1

[50] Prost, R.W., Mark, L.P., Rand, S.D., Kim, T.A. and Haughton, V.M. (1997) Recent Advances in MR Spectroscopy Expand Its Applications in Neurologic Disease. WMJ: Official Publication of the State Medical Society of Wisconsin, 96, 41-45.

[51] Levin, D.C., Spettell, C.M., Rao, V.M., Sunshine, J., Bansal, S. and Busheé, G.R. (1998) Impact of MR Imaging on Nationwide Health Care Costs and Comparison with Other Imaging Procedures. AJR American Journal of Roentgenology, 170, 557-560. http://dx.doi.org/10.2214/ajr.170.3.9490930

[52] Arenson, R.L., Lu, Y., Elliott, S.C., Jovais, C. and Avrin, D.E. (2001) Measuring the Academic Radiologist’s Clinical Productivity: Applying RVU Adjustment Factors. Academic Radiology, 8, 533-540. http://dx.doi.org/10.1016/S1076-6332(03)80628-1

[53] Eisenberg, J.M. (1989) Clinical Economics. A Guide to the Economic Analysis of Clinical Practices. JAMA, 262, 2879-2886. http://dx.doi.org/10.1001/jama.1989.03430200123038

[54] Weinstein, M.C. and Stason, W.B. (1977) Foundations of Cost-Effectiveness Analysis for Health and Medical Practices. New England Journal of Medicine, 296, 716-721. http://dx.doi.org/10.1056/NEJM197703312961304

[55] Garrison Jr., L.P., Bresnahan, B.W., Higashi, M.K., Hollingworth, W. and Jarvik, J.G. (2011) Innovation in Diagnostic Imaging Services: Assessing the Potential for Value-Based Reimbursement. Academic Radiology, 18, 1109-1114. http://dx.doi.org/10.1016/j.acra.2011.04.007

[56] Forman, H.P. (2006) MRI and CT Imaging: How Fast Can Reimbursement Be Cut? AJR American Journal of Roentgenology, 187, 601-602. http://dx.doi.org/10.2214/AJR.06.0915

[57] Blankart, R., Schreyogg, J. and Busse, R. (2008) Performance of Reimbursement Schemes in Valuation of Technologies: The Example of Magnetic Resonance Imaging. Technology and Health Care, 16, 171-182.

[58] Pearce, J.W. (2012) The Return of Capitation Preparing for Population-Based Health Care. Healthcare Financial Management, 66, 50-57.

[59] Silverman, S.G., Deuson, T.E., Kane, N., Adams, D.F., Seltzer, S.E., Phillips, M.D., Khorasani, R., Zinner, M.J. and Holman, B.L. (1998) Percutaneous Abdominal Biopsy: Cost-Identification Analysis. Radiology, 206, 429-435. 
http://dx.doi.org/10.1148/radiology.206.2.9457196

[60] van Erkel, A.R., van Rossum, A.B., Bloem, J.L., Kievit, J. and Pattynama, P.M. (1996) Spiral CT Angiography for Suspected Pulmonary Embolism: A Cost-Effectiveness Analysis. Radiology, 201, 29-36. http://dx.doi.org/10.1148/radiology.201.1.8816516

[61] Vanninen, R., Manninen, H. and Soimakallio, S. (1995) Imaging of Carotid Artery Stenosis: Clinical Efficacy and Cost-Effectiveness. AJNR American Journal of Neuroradiology, 16, 1875-1883.

[62] Baldini, C.G. and Culley, E.J. (2011) Estimated Cost Savings Associated with the Transfer of Office-Administered Specialty Pharmaceuticals to a Specialty Pharmacy Provider in a Medical Injectable Drug Program. Journal of Managed Care Pharmacy, 17, 51-59.

[63] Chesson, H.W., Blandford, J.M., Gift, T.L., Tao, G.Y. and Irwin, K.L. (2004) The Estimated Direct Medical Cost of Sexually Transmitted Diseases among American Youth, 2000. Perspectives on Sexual and Reproductive Health, 36, 11-19. http://dx.doi.org/10.1363/3601104

[64] Russi, T.J., Libby, D.M. and Henschke, C.I. (1997) Clinical Utility of Computed Tomography in the Diagnosis of Pulmonary Embolism. Clinical Imaging, 21, 175-182. http://dx.doi.org/10.1016/S0899-7071(96)00014-9

[65] Rubens, D.J., Strang, J.G., Fultz, P.J. and Gottlieb, R.H. (1997) Sonographic Guidance of Mediastinal Biopsy: An Effective Alternative to CT Guidance. AJR American Journal of Roentgenology, 169, 1605-1610. http://dx.doi.org/10.2214/ajr.169.6.9393174

[66] Dwamena, B.A., Kloos, R.T., Fendrick, A.M., Gross, M.D., Francis, I.R., Korobkin, M.T. and Shapiro, B. (1998) Diagnostic Evaluation of the Adrenal Incidentaloma: Decision and Cost-Effectiveness Analyses. Journal of Nuclear Medicine, 39, 707-712.

[67] Litwin, M.S., Kahn, K.L. and Reccius, N. (1993) Why Do Sicker Patients Cost More? A Charge-Based Analysis of Patients Undergoing Prostatectomy. Journal of Urology, 149, 84-88.

[68] Yin, D. and Forman, H.P. (1995) Health Care Cost-Benefit and Cost-Effectiveness Analysis: An Overview. Journal of Vascular and Interventional Radiology, 6, 311-320. http://dx.doi.org/10.1016/S1051-0443(95)72814-7

[69] Topol, E.J., Leya, F., Pinkerton, C.A., Whitlow, P.L., Hofling, B., Simonton, C.A., et al. (The CAVEAT Study Group) (1993) A Comparison of Directional Atherectomy with Coronary Angioplasty in Patients with Coronary Artery Disease. New England Journal of Medicine, 329, 221-227. http://dx.doi.org/10.1056/NEJM199307223290401

[70] Guzman, L.A., Simpfendorfer, C., Fix, J., Franco, I. and Whitlow, P.L. (1994) Comparison of Costs of New Atherectomy Devices and Balloon Angioplasty for Coronary Artery Disease. American Journal of Cardiology, 74, $22-25$. http://dx.doi.org/10.1016/0002-9149(94)90485-5

[71] Hunink, M.G., Cullen, K.A. and Donaldson, M.C. (1994) Hospital Costs of Revascularization Procedures for Femoropopliteal Arterial Disease. Journal of Vascular Surgery, 19, 632-641. http://dx.doi.org/10.1016/S0741-5214(94)70036-2

[72] Brasel, K.J. and Weigelt, J.A. (1996) Blunt Thoracic Aortic Trauma. A Cost-Utility Approach for Injury Detection. JAMA Surgery, 131, 619-625. http://dx.doi.org/10.1001/archsurg.1996.01430180045007

[73] Shwartz, M., Young, D.W. and Siegrist, R. (1995) The Ratio of Costs to Charges: How Good a Basis for Estimating Costs? Inquiry, 32, 476-481.

[74] Schimmel, V.E., Alley, C. and Heath, A.M. (1987) Measuring Costs: Product Line Accounting versus Ratio of Cost to Charges. Topics in Health Care Financing, 13, 76-86.

[75] Yin, D., Baum, R.A., Carpenter, J.P., Langlotz, C.P. and Pentecost, M.J. (1995) Cost-Effectiveness of MR Angiography in Cases of Limb-Threatening Peripheral Vascular Disease. Radiology, 194, 757-764. http://dx.doi.org/10.1148/radiology.194.3.7862975

[76] Rogers, H.W. and Coldiron, B.M. (2009) A Relative Value Unit-Based Cost Comparison of Treatment Modalities for Nonmelanoma Skin Cancer: Effect of the Loss of the Mohs Multiple Surgery Reduction Exemption. Journal of the American Academy of Dermatology, 61, 96-103. http://dx.doi.org/10.1016/j.jaad.2008.07.047

[77] Rubin, G.D., Armerding, M.D., Dake, M.D. and Napel, S. (2000) Cost Identification of Abdominal Aortic Aneurysm Imaging by Using Time and Motion Analyses. Radiology, 215, 63-70. http://dx.doi.org/10.1148/radiology.215.1.r00ap4863 
Scientific Research Publishing (SCIRP) is one of the largest Open Access journal publishers. It is currently publishing more than 200 open access, online, peer-reviewed journals covering a wide range of academic disciplines. SCIRP serves the worldwide academic communities and contributes to the progress and application of science with its publication.

Other selected journals from SCIRP are listed as below. Submit your manuscript to us via either submit@scirp.org or Online Submission Portal.
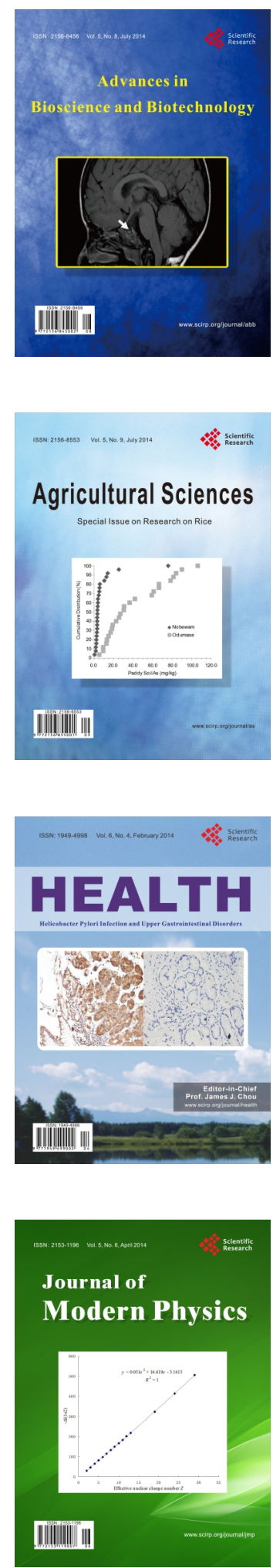
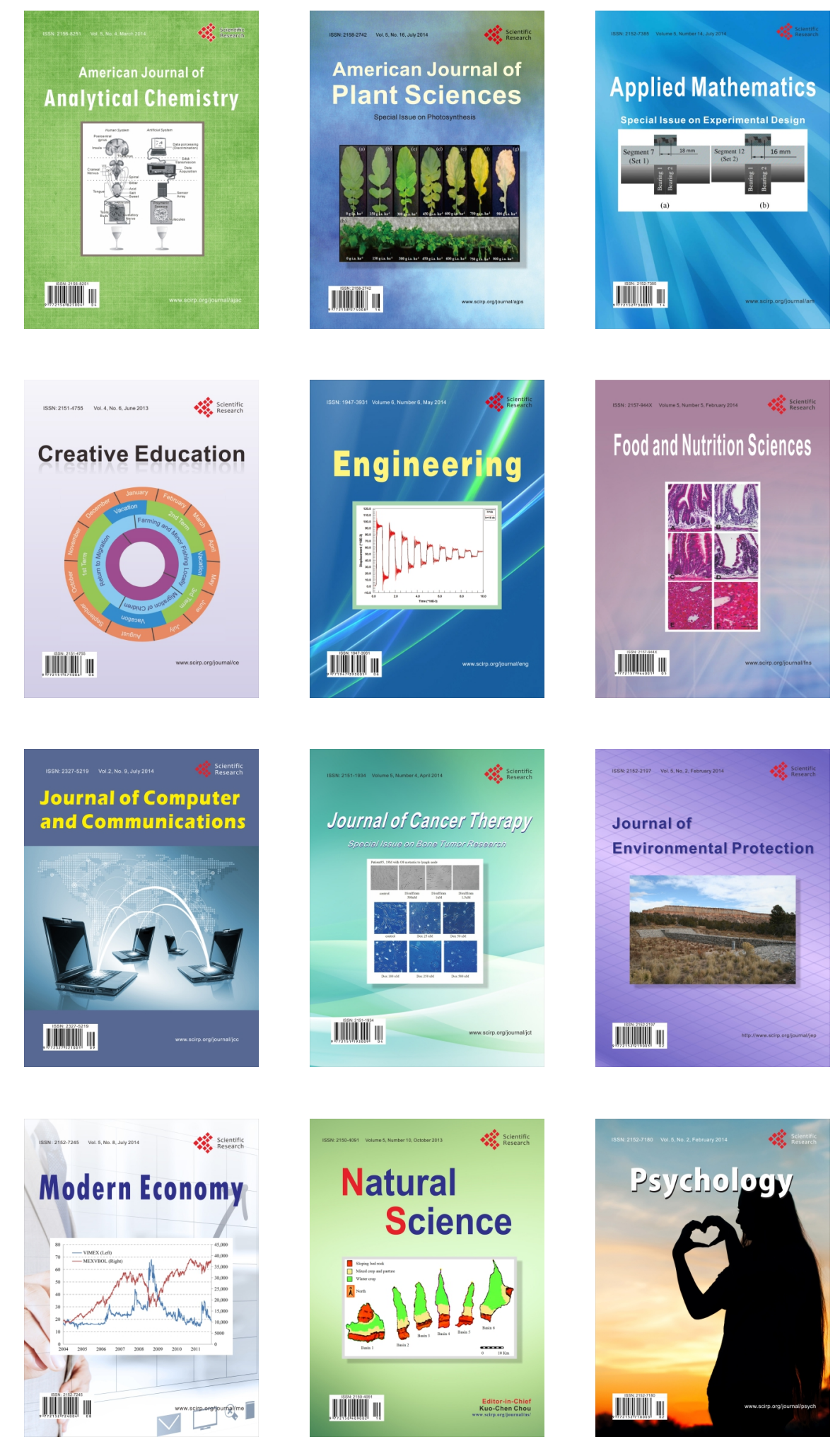